\title{
The Development of Sports Associations in Medical Colleges with the "Three Orientations" Talent Cultivation Model
}

\author{
Xin $\mathrm{Li}^{1,}$, Jingjing Guan ${ }^{1, b}$ \\ ${ }^{1}$ Qiqihar Medical University, Qiqihar City, Heilongjiang Province, 161006, China \\ aemail:360121833@qq.com \\ bemail:33094995@qq.com
}

Keywords: "three orientations"; talent cultivation; medical colleges; sports association

\begin{abstract}
The so-called "three orientations" refers to the "professionalism"-oriented humanistic quality education, the "practice competence"-oriented professional quality training and the "social adaptation"-oriented physical and mental quality development. The "three orientations" talent cultivation model was created by the Qiqihar Medical University. Since the Qiqihar Medical University implemented the "three orientations" talent cultivation model in 2011, it has made many fruitful attempts in student education and teaching and curriculum reform. The university has achieved certain results and got peer support and recognition. Based on the author's learning and practical experience, this article first interprets the specific connotation of "three orientations" and then proposes the development countermeasures for sports associations in medical college.
\end{abstract}

\section{Introduction}

The assessment of students' comprehensive quality is the measurement and evaluation of students' performance in all aspects during their school days. The evaluation results can be used as an important basis for students' award evaluation, recommendation for exchange program and employment recommendation for graduates. The National Medium- and Long-Term Plan for Education Reform and Development emphasizes the concept of educating people with the priority of moral education, with the importance of ability training and with overall development. The qualified doctors trained in the new century should be fully-developed medical students. In 2011, Qiqihar Medical University creatively proposed the "three orientations" talent cultivation model with the goal of "students' future development", which further deepens the understanding of medical education on "moral education, intellectual education and sports". In order to better stimulate and mobilize the subjective initiative of the students and reflect the educational effect of the "three-orientations" talent cultivation model of the college, the college revised the comprehensive quality assessment method.

\section{Interpretation of the Specific Connotation of "Three Orientations"}

\subsection{Effectively grasping talent cultivation objectives under the guidance of position competence}

Qiqihar Medical University built a "three orientations" cultivation model that aims at the future development of students and focuses on cultivating applied medical talents with good professional qualities, preliminary clinical abilities, lifelong learning abilities and social adaptability. In the educational ideology, it adheres to the "four unifications": the unification of basic knowledge and position competency, the unification of medical literacy and humanistic literacy, the unification of all-round development and personality development, and the unification of scientific spirit and professional spirit. The educational concept has achieved "three changes": the change from teacher-centered one to student-centered one; the change from teaching knowledge to developing ability; the change from passive learning to active learning. 


\subsection{Optimizing and integrating curriculum system with the goal of students' comprehensive development}

Taking professional ethics as the starting point, the medical college will establish a complete education system for professional cognition education, professional emotional education and career development education. The school will refine theoretical teaching, prolong practice hours and keep this for five years to achieve "three combinations": the combinations of practical teaching with students' realistic performance, with the cultivation of medical professional ethics and with daily activities. To promote the integration of basic medicine and clinical medicine, and cultivate students' scientific thinking and practical ability, the school will rely on dual-qualified teachers to build seven course groups: natural sciences, basic medicine, clinical medicine, public health, scientific method education, practical skills training and graduation practice. The medical college will pay attention to the cultivation of comprehensive clinical ability and systematically integrate basic and clinical knowledge to form nine system modules, including circulation, respiration, digestion, blood, urinary, endocrine, reproductive, nervous and exercise. Then, the school will use standardized patients to conduct OSCA assessment for students, so as to guide and motivate students to become scientific research assistants and participate in the research activities of teachers. This will fully cultivate medical students' professional skills, clinical thinking ability and scientific research capabilities. In order to cultivate doctors who respect life and health, and have good psychological qualities and social adaptability, the school will carry out diverse courses of military, sports, life education, psychology and safety education. By encouraging students to participate in various mental health lectures, training and counseling activities, the school will cultivate medical students with good psychological quality and sound personality.

\subsection{Promoting the reform of teaching methods with educational resources as a way}

The school should use information technology, network television stations, teaching resources and digital libraries to build an online platform for teaching and independent learning for students. It ought to use multimedia, teaching models and other means to promote the "student-centered" and "self-learning" education. Heuristic way, experiential method, inquiry, group discussion, bedside teaching, PBL, TBL, evaluation teaching, clinical simulation teaching, special lecture teaching and other teaching methods are used to enhance teacher-student interaction and cultivate students' abilities of discovery, analysis and solving of problem, self-learning ability and team awareness. The school should break the professional boundaries, integrate and optimize laboratory resources, and build 10 multifunctional experimental teaching centers to meet the students' needs for independent learning, skills training, scientific spirit, innovative ability, thinking ability, practical ability, professional quality, comprehensive quality training and social services.

\subsection{Improving teaching and evaluation mechanisms based on teaching quality}

The whole process of integrating the concept of overall quality management into teaching management will help establish and improve the monitoring and evaluation system for internal and external teaching quality. The school conducts teaching inspections at the early, middle and final semester and carries out various special assessments on teaching quality. The college needs to adopt diverse assessment evaluation methods based on competence to make teaching quality management work normal and standardized. This effectively guarantee the training quality for special applied talents. The school should improve the quality standards of the teaching through the quality monitoring, assessment, analysis, feedback and continuous improvement and it needs to accept assessments of external experts to promote the quality of school teaching in assessment of teaching, learning and management. 


\section{Development Countermeasures for Sports Associations in Medical Colleges}

\subsection{To pay attention to the development of student associations and provide convenience for the growth of student associations}

If it is possible, the school should provide convenience for the development of student associations as much as possible, such as setting up special funds, giving permission for them to use more sites and arranging teachers with work experience or professional expertise in this area to supervise and guide the activities of sports associations. The school needs to convene relevant student work conferences and regularly learn more feedback from primary-level organizations.

\subsection{To put service as a focus of student associations and broaden the platform for the association development}

The relevant departments of the school must complete the transformation of functions: a change from management to service. Sports associations are organizations formed by students with the same hobbies and hobbies voluntarily. Students are often together to share the joy of sports. The self-management is particularly obvious and has a certain exclusive nature. It is difficult to do a good job in the work of associations from the perspective of management. They should take the initiative to serve them, share more association information with them and provide sufficient social business resources to effectively solve their problems of outside communication and funding source.

\subsection{To control the number of associations and guarantee the quality of activities}

First of all, a strict review of the establishment of the association and careful verification of the reported information will ensure the quality of activities which students will participate in. The college needs to put quality before quantity. The relevant departments are responsible for the students and must carry out their work. After all, the school's sports facilities and venues are limited. With the limited resources, the school should make similar sports associations compete to promote their improvement of mechanisms, change their activity forms and improve the quality of their activities. The school needs to maintain the good image of the association in the minds of students and to meet the students' needs for recreational and sports activities. The college can establish related service supervision mechanisms, such as the social contact person system in Jilin University. The school arranges a school contact person for each association to ensure that each association can keep in touch with the school at the first time. They can feed back their difficulties. Moreover, it will provide strong supervision and guidance of the association.

\subsection{To enhance the sense of ownership of association members and create a good association culture}

Each association has its own culture, which is a kind of inheritance. Currently, students are increasingly ignoring the association culture. For them. The association is just a choice to have fun in their leisure time. As a sports association, team awareness, cooperation spirit and sense of responsibility are particularly important and these are exactly what sports associations neglect. While developing itself, the association must cultivate a sense of belonging and ownership among their members. Everyone is united and takes responsibility for themselves. This is another new topic on the development of associations in Jilin University.

\subsection{To regulate external activities of the association, and correctly guide and supervise them}

In today's information-based society, communication has become quick and easy. Associations have many opportunities for external exchange and cooperation in the process of continuous development and growth. In particular, performance sports associations often have the opportunity to participate in performances. In order to expand their influence, many associations have great blindness in the choice of external activities. They often have unnecessary troubles. They fail to achieve the expected results and cause losses to the interests of the association. The most important 
thing is that there is no guarantee of personal safety for a large number of members who go out to participate in the performance. Relevant departments should pay attention to it and increase supervision. Association contact person should keep abreast of the activity of the association and prevent unnecessary trouble.

\subsection{To establish correct values and increase training and education}

As long as it is an organization, there will be mechanisms and a division of power, and so will associations. The place where everyone was originally together to share happiness and help each other has become vanity fairs. It will cause the cohesiveness of the association to decline. Members will be seriously lost and students will become utilitarian. Therefore, associations will have a great negative impact on students. The contact person must correctly guide and master the activities, do a good job of training, regularly hold related conferences, promote association culture and correct association work awareness. Student associations are intermediary organizations for schools and social organizations to carry out ideological and political education. They are like bridges between schools, society and students. The development of student associations requires extensive support and encouragement from the government, society and schools. Therefore, the school should encourage more students to move toward this second class, mobilize their enthusiasm and guide students to participate in association activities. Sports associations which are beneficial to students' physical and mental health, should also receive the support and attention of the school.

\section{Conclusion}

Since Qiqihar Medical University implemented the "three-orientations" talent cultivation model in 2011, many fruitful attempts have been made in student education and teaching and curriculum reform. Although there are some problems in the development of sports associations in Qiqihar Medical University, we should divide the issue into subjective and objective one. The school should focus on three aspects. One is to understand the development status of the sports associations in depth and to give the greatest support to the development of the associations. The second is to increase training and education and to standardize the development of associations. At the same time, the school needs to use sports association activities to mobilize students' enthusiasm to participate in sports.

\section{Acknowledgements}

(1) Source: Heilongjiang Province Education Science "13th Five-Year Plan"(2016 annual record of the project); Title of the project: Research on the Development and Service supply of Sports Associations in Medical Colleges and Universities under the Mode of Three Orientations Talent training; Subject number: GBC1317228.

(2) Project source: funding from the humanities and social science research project of Heilongjiang Provincial Education Department in 2016. Project name: Research on analysis and service provision on sports participation of urban residents in Heilongjiang. Subject number: No.2016-KYYWF-0898.

\section{References}

[1] Sun Juntao, Yang Chao. A Research on the Development of Occupational Practical Sports Curriculum with the "Three Orientations" Talent Cultivation Model [J]. Sports, 2017, (22): 79-80.

[2] Bai Yanjing, Yun Changhai, Xu Qinggang, Zhang Xiaojie, Liu Chunmiao, Liu Fu. A Research on the Construction of Curriculum Evaluation Index System with the "Three Orientations" Talent Cultivation Model [J]. Medical Education Management, 2017, (04): 259-261+ 267.

[3] Wang Lei. An Investigation and Research on the Current Status of Sports Association Activities in Yan'an University [J]. Journal of Yan'an University (Natural Science Edition), 2017, (02): 
116-120.

[4] Sui Nana, Ji Hui, Li Chaojun. A Research on Students' Participation in Teaching Management with the "Three Orientations" Talent Cultivation Model [J]. Science and Technology Innovation Herald, 2016, (03): 157-158.

[5] Guan Yingli. An Investigation and Analysis of the Status of Student Sports Associations in Liaocheng University [J]. Contemporary Sports Technology, 2016, (03): 102-103.

[6] Liu Dan, Zhao Zhongxin, Zheng Lihong, Chen Ping, Mei Qingbu, Ji Hui, Gao Yin, Li Tao. A Study on Practice of Medical Cell Biology Teaching Reform with the "Three Orientations" Talent Cultivation Model [J]. China Higher Medical Education, 2015, (06): 63-64.

[7] Jiang Fengqi, Zhao Zhiqiu. A Research on the Development Status and Countermeasures of Sports Associations in Jilin University [J]. Journal of Changchun Education Institute, 2013, (17): 13-14. 